\title{
Tobacco smoking and depression during pregnancy
}

\author{
Tabagismo e depressão durante a gravidez
}

\author{
Karen Jansen, ${ }^{1}$ Aline Rezende Curra, ${ }^{2}$ Luciano Dias de Mattos Souza, ${ }^{3}$ Ricardo Tavares Pinheiro, ${ }^{4}$ Inácia \\ Gomes da Silva Moraes, ${ }^{3}$ Myriam Siqueira da Cunha, ${ }^{5}$ Ricardo Azevedo da Silva ${ }^{6}$
}

${ }^{1}$ Mestre em Saúde e Comportamento. Doutoranda, Programa de Pós-Graduação em Saúde e Comportamento, Universidade Católica de Pelotas, Pelotas, RS, Brazil. ${ }^{2}$ Mestre em Saúde e Comportamento. Professora, Universidade Federal do Pampa, Bagé, RS, Brazil. ${ }^{3}$ Mestre em Saúde e Comportamento. Professor(a), Universidade Católica de Pelotas. ${ }^{4}$ Doutor em Psiquiatria Clínica. Professor, Universidade Católica de Pelotas. ${ }^{5}$ Doutora. Professora, Universidade Católica de Pelotas. ${ }^{6}$ Doutor em Psicologia. Professor, Universidade Católica de Pelotas.

\begin{abstract}
Objectives: To evaluate the association between cigarette smoking and depression in pregnant women and to identify associated factors. Method: This was a cross-sectional study including 1,264 pregnant women assisted by the public health service in the municipality of Pelotas, Brazil. Depression was evaluated using the Edinburgh Postnatal Depression Scale. Cigarette consumption was assessed using open questions. Poisson regression was used to analyze the data.

Results: The prevalence of depression during pregnancy was $21.2 \% ; 19.3 \%$ of the depressed women were smokers. Women who smoked during pregnancy showed a 1.72 -fold (95\% confidence interval: $1.27-2.34)$ higher probability of being depressed.

Conclusion: Our findings suggest a positive relationship between cigarette smoking and depression symptoms in pregnant women.

Keywords: Depression, pregnancy, smoking, cross-sectional studies.

\section{Resumo}

Objetivos: Avaliar a associação entre consumo de cigarros e depressão durante a gravidez e identificar fatores associados.

Método: Trata-se de estudo transversal, que incluiu uma população de 1.264 gestantes atendidas nos serviços de maior fluxo do Sistema Único de Saúde (SUS) da cidade de Pelotas (RS), Brasil. A depressão foi avaliada utilizando a Edinburgh Postnatal Depression Scale, e o consumo de tabaco foi verificado através de questões abertas. Na análise estatística, utilizou-se a regressão de Poisson.

Resultados: A prevalência de depressão durante a gestação foi de 21,2\%; 19,3\% das gestantes com depressão eram fumantes. As mulheres que fumaram durante a gravidez apresentaram 1,72 (intervalo de confiança de 95\%: 1,27-2,34) maior probabilidade de ter depressão.

Conclusão: Os resultados indicam uma relação positiva entre o consumo de cigarros durante a gravidez e episódios depressivos.

Descritores: Depressão, gravidez, tabagismo, estudos transversais.
\end{abstract}

\section{Introduction}

Depression has been identified as a public health problem because of its high prevalence, mainly among women. ${ }^{1}$ Estimates have shown that one out of five women will present at least one depression episode in their lifetime, usually at the reproductive stage, between 20 and 40 years of age. ${ }^{2}$ Previous studies have shown that $19 \%$ of pregnant women present high depressive symptoms. ${ }^{3}$

Pregnant women with depressive symptoms are more likely to present harmful behavior during the antenatal period when compared with those without depression. Some women seek relief to depressive symptoms through self-medication or by making use of substances such as cigarettes, alcohol, marijuana, or other illicit drugs. ${ }^{4}$

Epidemiological studies suggest that smoking during pregnancy is associated with a higher incidence of obstetric complications such as miscarriage, ectopic pregnancy, preterm babies, placental abruption, premature rupture of membranes, and fetal death. ${ }^{5}$ Developmental risks for the child, including increased risk for asthma and bronchitis, have also been suggested. ${ }^{6}$

Tobacco consumption during pregnancy may also affect the baby's cognitive and behavioral development during

Correspondência:

Karen Jansen, Rua Almirante Barroso, 1202, sala 109, CEP 96010-280, Pelotas, RS, Brazil. Tel.: +55 (53) 2128.8404. E-mail: karenjansen315@hotmail.com

No conflicts of interest declared concerning the publication of this article.

Copyright (C) Revista de Psiquiatria do Rio Grande do Sul - APRS

Submitted Jan 21, 2010. Accepted Feb 03, 2010. 
childhood. ${ }^{7}$ Children exposed to nicotine at a very early age are more predisposed to cognitive impairment. These children may also present anti-social behavior, attention deficit/hyperactivity disorder (ADHD), and panic disorders in adolescence. ${ }^{8}$

Most pregnant women seem to worry about the negative consequences associated with the use of tobacco; however, only $30 \%$ of them try to quit smoking after becoming aware of the pregnancy. ${ }^{9}$ Although pregnancy is a motivator to quit smoking, a recent study has shown that the percentage of pregnant women who actually quit smoking is not meaningful when compared to the general population. ${ }^{10}$

There is a higher prevalence of cigarette consumption among depressive women than among those with no sign of depression. ${ }^{11}$ However, there are few studies available focused on investigating the prevalence of depressive symptoms among pregnant women who smoke.

Therefore, the objectives of the present study were 1) to evaluate the association between cigarette consumption, or the number of cigarettes smoked, and depression in pregnant women, and 2) to identify other factors which may also be associated with depression during pregnancy.

\section{Methods}

The present cross-sectional study was carried out with the pregnant women population assisted by the public health service in the municipality of Pelotas, state of Rio Grande do Sul, southern Brazil. The city has a population of 350,000 inhabitants, of which more than $96 \%$ live in the urban area. ${ }^{12}$

Pregnant women assisted by the Brazilian public Unified Health System (Sistema Único de Saúde) at any unit within the urban area of Pelotas from August 2006 to August 2007 were contacted and invited to participate in the study. Women who did not live in the urban area of the city or who showed any difficulties in understanding and answering the questionnaire (e.g. due to illiteracy) were excluded, and only those women who provided signed consent were allowed to answer the questionnaire. Patients with less than 18 years of age had the consent provided by a parent or legal guardian. The research protocol was approved by the Ethics Committee at Universidade Católica de Pelotas, and pregnant women who showed symptoms of depression were referred to the psychiatric service of the university hospital, Hospital São Francisco de Paula.

Perinatal information was collected by means of a structured interview made by graduate students of psychology. The interview comprised questions on maternal age, schooling, marital status, pregnancy planning, abortion thoughts, and other health behaviors. In order to assess the socioeconomic situation of pregnant women, an instrument validated by the Associação Brasileira de Empresas de Pesquisa $(\mathrm{ABEP})^{13}$ was used. The instrument classifies individuals according to some consumption items present at their homes, such as television, refrigerator, automobile and other items, and also according to the level of education of the person with highest income in the family. In this sample, the socioeconomic status of the families was divided into three categories: high, medium, and low, according to terciles of a continuum score.

At the end of the interview, participants were given a self-reported instrument containing the Edinburgh Postnatal Depression Scale (EPDS), ${ }^{14}$ which was used to measure depressive symptomatology. EPDS is a self-applied scale composed of 10 topics whose options are scored from 0 to 3 (Likert scale) according to the presence or intensity of depressive symptoms. The questions evaluate depressive and dysphoric mood, sleep disorders, loss of pleasure, thoughts regarding death and suicide, reduced performance in everyday tasks, and guilt. The psychometric validity of the scale is of $60 \%$ for a positive predictive value to evaluate depression at a cutoff point of $\geq 13$ (59.5\% sensitivity, $88.4 \%$ specificity). Binary outcomes were used in the present study, and the sample was divided into two groups, pregnant women with symptoms suggestive of depression (EPDS $\geq 13$ ) and women without symptoms suggestive of depression (EPDS $<13$ ).

Tobacco consumption was investigated by the questions "Have you been smoking cigarettes lately?" and "In general, how many cigarettes a day do you smoke?" The second question was changed to an ordinal variable with three categories: (I) no cigarette consumption, (II) consumption of 1 to 10 cigarettes/day, and (III) consumption of more than 11 cigarettes/day.

The Epi-Info 6.04d software was used to enter the data (twice) and to automatically validate the amplitude and consistency of data. Statistical analyses were performed using the Stata 9 software. After obtaining the simple frequency of all variables, a gross analysis was performed using the chi-square test. In the adjusted analysis, because the prevalence of depression was higher than $10 \%$, Poisson regression was used to evaluate the prevalence ratio of independent variables associated with the outcome (indicative of depression). Variables showing $\mathrm{p}<$ 0.2 in the gross analysis were included in the adjusted analysis, in which significance was set at $\mathrm{p}<0.05$.

Three hierarchic levels were used in the adjusted analysis to assess the association between number of cigarettes smoked and depressive symptoms: the first level comprised socioeconomic and demographic variables; the second comprised gestational variables; and the third one included information regarding tobacco consumption.

\section{Results}

A total of 1,340 pregnant women enrolled in the Prenatal Program of the Brazilian public Unified Health System at any unit within the urban area of Pelotas from August 2006 to August 2007 were contacted. Of these, $76(6 \%)$ refused to participate or were excluded, resulting in a final sample of 1,264 women. Table 1 shows the study results. 
Of the 1,264 women assessed, 268 (21.2\%) were classified as presenting depressive symptoms (EPDS $\geq 13$ ) during pregnancy. The women assessed were $25 \pm 6.5$ years old and were in their $27.7 \pm 9.4$ weeks of pregnancy. Forty three percent of the sample had a low educational level (had not finished elementary school; $n=539), 53.7 \%$ were classified as medium socioeconomic class $(\mathrm{n}=674)$, and $73.3 \%$ of the women were married or lived with a partner $(n=923)$. Of the total number of patients, $56.8 \%$ were in the third trimester of pregnancy $(n=691)$, and $43.3 \%$ were primiparous $(n=542)$.

In relation to tobacco consumption, $53.2 \%$ of the pregnant women had never smoked $(n=672), 27.5 \%$ had smoked but then stopped $(\mathrm{n}=348)$, and $19.3 \%$ were smoking during pregnancy $(n=244)$. There was a high proportion of women who stopped smoking because of the pregnancy (54.9\%). In the group of smokers, the average cigarette consumption was of $11 \pm 9.2$ cigarettes/day.

The prevalence of cigarette consumption increased as the pregnancy approached its term $(p=0.014)$, and was distributed as follows: $11.0 \%$ in the first trimester, $17.9 \%$ in the second trimester, and $20.2 \%$ in the third trimester of pregnancy.

In the adjusted analysis, most variables under study were associated with depression, with the exception of socioeconomic situation $(p=0.330)$ and pregnancy trimester $(p=0.105)$.
Our sample showed a higher prevalence of depression for women who were 35 years old or older compared with pregnant teenagers $(p=0.002)$. Schooling was also associated with depressive symptoms: the lower the educational level of pregnant women, the higher the number of participants with symptoms suggestive of depression. Women who did not live with a partner had a significantly higher proportion of high depressive symptoms $(p=0.001)$. In the same direction, non-primiparous mothers presented a significantly higher proportion of high depressive symptoms $(\mathrm{p}=0.000)$.

A statistically significant association was observed between consumption of cigarettes and symptoms indicative of depression. This association occurred independently of the influence of age, schooling, socioeconomic level, living with partner, pregnancy trimester, and first pregnancy. Women who reported smoking 1-10 cigarettes/day had a $46 \%$ higher proportion of presenting symptoms indicative of depression than nonsmokers (prevalence ratio, PR: 1.46; 95\% confidence interval, 95\%CI: 1.10-1.94). Likewise, the number of pregnant women with symptoms indicative of depression was $72 \%$ higher among women who reported smoking 11 or more cigarettes/day when compared with nonsmokers (PR: 1.72; 95\%CI: 1.27-2.34).

Table 1 - Distribution of variables in correlation with prevalence of depression and relationship with tobacco consumption during pregnancy

\begin{tabular}{|c|c|c|c|c|c|c|}
\hline Variable & $\begin{array}{l}\text { Responses } \\
\text { n (\%) }\end{array}$ & $\begin{array}{c}\text { EPDS } \geq 13 \\
\text { n }(\%)\end{array}$ & $\begin{array}{c}\text { Crude PR } \\
(95 \% \text { CI) }\end{array}$ & $\mathbf{p}$ & $\begin{array}{c}\text { Adjusted PR } \\
(95 \% \mathrm{CI})\end{array}$ & $\mathbf{p}$ \\
\hline \multicolumn{7}{|l|}{ First hierarchical level } \\
\hline Age* & & & 0.096 & & 0.002 & \\
\hline $12-19$ years old & $287(22.8)$ & $54(18.8)$ & 1.00 & & 1.00 & \\
\hline 20-34 years old & $854(67.7)$ & $181(21.1)$ & $1.13(0.86-1.48)$ & & $1.42(1.08-1.87)$ & \\
\hline $35-45$ years old & $120(9.5)$ & $32(26.7)$ & $1.42(0.97-2.08)$ & & $1.73(1.18-2.54)$ & \\
\hline Schooling* & & & & 0.000 & & 0.000 \\
\hline Incomplete elementary school & $539(43.2)$ & $147(27.3)$ & $2.21(1.63-2.99)$ & & $2.15(1.56-2.96)$ & \\
\hline Complete elementary school/incomplete high school & $338(27.0)$ & $71(21.0)$ & $1.70(1.21-2.39)$ & & $1.70(1.21-2.40)$ & \\
\hline Complete high school/undergraduate student & $373(29.8)$ & $46(12.3)$ & 1.00 & & 1.00 & \\
\hline Socioeconomic situation* & & & & 0.001 & & 0.330 \\
\hline High & $122(9.7)$ & $16(13.1)$ & 1.00 & & 1.00 & \\
\hline Medium & $674(53.7)$ & $133(19.7)$ & $1.50(0.93-2.43)$ & & $1.17(0.72-1.90)$ & \\
\hline Low & $459(36.6)$ & $117(25.5)$ & $1.94(1.20-3.15)$ & & $1.27(0.77-2.08)$ & \\
\hline Living with partner & & & & 0.001 & & 0.001 \\
\hline No & $337(26.7)$ & $92(27.3)$ & $1.46(1.17-1.81)$ & & $1.46(1.17-1.83)$ & \\
\hline Yes & $923(73.3)$ & $173(18.7)$ & 1.00 & & 1.00 & \\
\hline \multicolumn{7}{|l|}{ Second hierarchical level } \\
\hline Pregnancy period* & & & & 0.104 & & 0.105 \\
\hline Up to 14 weeks & $146(12.0)$ & $25(17.1)$ & 1.00 & & 1.00 & \\
\hline $15-28$ weeks & $380(31.2)$ & $93(24.5)$ & $1.43(0.96-2.13)$ & & $1.37(0.93-2.05)$ & \\
\hline 29 or more weeks & $691(56.8)$ & $138(20.0)$ & $1.17(0.79-1.72)$ & & $1.11(0.75-1.63)$ & \\
\hline First pregnancy & & & & 0.000 & & 0.001 \\
\hline No & $711(56.7)$ & $189(26.6)$ & $1.85(1.45-2.34)$ & & $1.62(1.23-2.15)$ & \\
\hline Yes & $542(43.3)$ & $78(14.4)$ & 1.00 & & 1.00 & \\
\hline \multicolumn{7}{|l|}{ Third hierarchical level } \\
\hline Cigarette consumption during pregnancy* & & & & 0.000 & & 0.000 \\
\hline No smoking & $1,090(81.4)$ & $182(17.9)$ & 1.00 & & 1.00 & \\
\hline $1-10$ cigarettes/day & $148(11.8)$ & $46(31.1)$ & $1.74(1.32-2.29)$ & & $1.46(1.10-1.94)$ & \\
\hline 11 cigarettes/day or more & $85(6.8)$ & $36(42.4)$ & $2.37(1.79-3.14)$ & & $1.72(1.27-2.34)$ & \\
\hline Total & $1,264(100)$ & $268(21.2)$ & - & - & - & - \\
\hline
\end{tabular}

95\% CI $=95 \%$ confidence interval; EPDS = Edinburgh Postnatal Depression Scale; $\mathrm{PR}=$ prevalence ratio.

* p value for linear tendency. 


\section{Discussion}

This study exclusively analyzed data collected in a group of pregnant women assisted by the public health system (mostly primary health care centers) in Pelotas, southern Brazil. Although an expressive sample was selected, the validity of the study design (cross-sectional study) is limited due a causality bias. Another important limitation of this study is related to the assessment of depression. Although EPDS has been frequently used as an instrument to evaluate depressive symptoms, the gold standard for the diagnosis of depression is a psychological or psychiatric evaluation.

There is evidence that multiple factors may lead to cigarette consumption during pregnancy, e.g. low educational level, not living with a partner, a negative attitude toward pregnancy, being a dependent smoker, and living with other smokers. ${ }^{15}$ Although quitting smoking is difficult, this study showed that $54.9 \%$ of the women had stopped smoking when they became aware of their pregnancy, a percentage that is higher to that reported by other authors. ${ }^{9}$ On the other hand, $19.3 \%$ of the women continued smoking, which is similar to the results found in other studies., ${ }^{2,5,15}$

Regarding depression, our results showed that the higher the number of cigarettes smoked daily, the more likely women were to present depression during pregnancy. Women who smoked showed a 1.72 -fold $(95 \%$ CI $1.27-2.34)$ higher probability of presenting symptoms indicative of depression when compared with nonsmokers. Although women were aware of the negative consequences of smoking on their own and on the child's health, most of the patients in our sample could not quit smoking even after they knew they were pregnant. This may be a result of the effect of nicotine on psychiatric symptoms, as suggested by a previous study that evaluated the impact of nicotine on psychiatric disorders and showed important relationships between cigarette consumption/tobacco dependency and some psychiatric disorders, such as common mental disorders (odds ratio, OR $=3.3)$, mood disorders $(\mathrm{OR}=2.5)$, major depression $(\mathrm{OR}=$ $2.07)$, dysthymia $(\mathrm{OR}=6.2)$, and panic disorders $(\mathrm{OR}=3.1){ }^{5}$ Another study compared women who spontaneously quit and women who continued smoking after learning about their pregnancy and found that smokers reported significantly more depression/anxiety symptoms than spontaneous quitters. ${ }^{16}$ These results suggest how difficult it is for smoking pregnant women to quit this habit, as it may be associated with mental disorders that were present prior to pregnancy.

There are many governmental campaigns in Brazil aimed at reducing smoking, and several studies have described different diseases caused by cigarette smoking. However, a more rigorous control is necessary in relation to pregnant women, especially in the sense of identifying possible mental disorders and concomitant cigarette use during prenatal consultations. In order to achieve this goal, it is important that health professionals involved in the care of pregnant women provide these patients with more than a mere clarification of the risks associated with smoking. Rather, these women should be referred to psychiatric or psychological treatment; without specialized assistance, they will hardly be able to cease tobacco smoking.

There is a clear dose-response relationship between the amount of cigarettes smoked daily by pregnant women and the presence of depression symptoms. Women aged 35 years or more, with a lower educational level, who are not married or do not live with a partner, as well as non-primiparous mothers and smokers comprise the population that is mostly in need of prevention strategies for depression.

\section{References}

1. Blazer DG, Kesler RC, McGonagle KA, Swartz MS. The prevalence and distribution of major depression in a national community sample. The National Comorbidity Survey. Am J Psychiatry. 2004;151:979-86.

2. Orr ST, Blazer DG, James AS, Reiter JP. Depressive symptoms and indicators of maternal health status during pregnancy. J Womens Health. 2007;16(4):535-42.

3. Faisal-Cury A, Menezes PR. Prevalence of anxiety and depression during pregnancy in a private setting sample. Arch Womens Ment Health. 2007;10:25-32.

4. Zuckerman B, Amaro H, Bauchner H, Cabral H. Depressive symptoms during pregnancy: relationship to poor health behavior. Am J Obstet Gynecol. 1998;160(5):1107-11.

5. Goodwin RD, Keyes K, Simuro N. Mental disorders and nicotine dependence among pregnant women in the United States. Obstet Gynecol. 2007;109(4):875-83.

6. Hofhuis W, de Jongste JC, Merkus PJ. Adverse health effects of prenatal and postnatal tobacco smoke exposure on children. Arch Dis Child. 2003;88:1086-90.

7. Button TM, Thapar A, McGuffin P. Relationship between antisocial behavior, attention-deficit hyperactivity disorder and maternal prenatal smoking. $\mathrm{Br} \mathrm{J}$ Psychiatry. 2005; 187:155-60.

8. Goodwin RD, Lewinsohn PM, Seeley JR. Respiratory symptoms and mental disorders among youth: results from a prospective, longitudinal study. Psychosom Med. 2004;66(6):943-9.

9. Dunn CL, Pirie PL, Lando H. Attitudes and perceptions related to smoking among pregnant and postpartum women in a low-income, multiethnic. Am J Health Promot. 1998; 12(4):267-74.

10. Haug K, Fugelli P, Aaro LE, Foss OP. Is smoking intervention in general practice more successful among pregnant than non-pregnant women? Fam Pract. 1994;11(2):111-6.

11. Borrelli B, Bock B, King T, Pinto B, Marcus BH. The impact of depression on smoking cessation in women. Am J Prev Med. 1996;12(5):378-87.

12. Instituto Brasileiro de Geografia e Estatística (IBGE) [Internet] [accessed 2007 June 30]. http://www.ibge.gov.br/cidadesat

13. Associação Brasileira de Empresas em Pesquisa (ABEP). Critério de classificação econômica no Brasil [Internet] [accessed 2007 June 30]. http://www.abep.org/ codigosguias/ABEP_CCEB.pdf

14. Santos IS, Matijasevich A, Tavares BF, Barros AJ, Botelho IP, Lapolli C, et al. Validation of the Edinburgh Postnatal Depression Scale (EPDS) in a sample of mothers from the 2004 Pelotas birth cohort study. Cad Saude Publica. 2007;23(11):2577-88.

15. Zhu SH, Valbo A. Depression and smoking during pregnancy. Addict Behav. 2002;27(4):649-58.

16. Linares Scott TJ, Heil SH, Higgins ST, Badger GJ, Bernstein IM. Depressive symptoms predict smoking status among pregnant women. Addict Behav. 2009;34(8):705-8. 